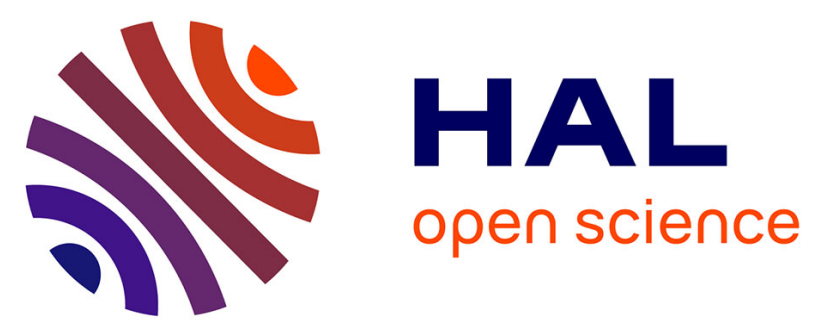

\title{
Intensive low-density lipoprotein cholesterol lowering in cardiovascular disease prevention: opportunities and challenges
}

Chris Packard, M John Chapman, Mahendra Sibartie, Ulrich Laufs, Luis Masana

\section{To cite this version:}

Chris Packard, M John Chapman, Mahendra Sibartie, Ulrich Laufs, Luis Masana. Intensive lowdensity lipoprotein cholesterol lowering in cardiovascular disease prevention: opportunities and challenges. Heart, 2021, pp.heartjnl-2020-318760. 10.1136/heartjnl-2020-318760 hal-03190302

\section{HAL Id: hal-03190302 https://hal.sorbonne-universite.fr/hal-03190302}

Submitted on 6 Apr 2021

HAL is a multi-disciplinary open access archive for the deposit and dissemination of scientific research documents, whether they are published or not. The documents may come from teaching and research institutions in France or abroad, or from public or private research centers.
L'archive ouverte pluridisciplinaire HAL, est destinée au dépôt et à la diffusion de documents scientifiques de niveau recherche, publiés ou non, émanant des établissements d'enseignement et de recherche français ou étrangers, des laboratoires publics ou privés. 


\title{
(2) OPEN ACCESS \\ Intensive low-density lipoprotein cholesterol lowering in cardiovascular disease prevention: opportunities and challenges
}

\author{
Chris Packard (1) , $M$ John Chapman, ${ }^{2}$ Mahendra Sibartie, ${ }^{3}$ Ulrich Laufs, ${ }^{4}$ \\ Luis Masana ${ }^{5}$
}

Institute of Cardiovascular and Medical Sciences, University of Glasgow, Glasgow, UK

2Endocrinology-Metabolism Division, Sorbonne University and Pitié-Salpetriere University Hospital, and National Institute for Health and Medical Research (INSERM), Paris, Île-de-France, France

${ }^{3}$ Amgen Europe, Rotkreuz, Switzerland

${ }^{4}$ Klinik und Poliklinik fur Kardiologie, University Clinic Leipzig, Leipzig, Sachsen, Germany

${ }^{5}$ Vascular Medicine and Metabolism Unit, Sant Joan University Hospital of Reus, Reus, Catalunya, Spain

\section{Correspondence to}

Chris Packard, University of Glasgow, Glasgow G12 8TA UK

Chris.Packard@glasgow.ac.uk

Received 16 December 2020 Revised 18 February 202 Accepted 20 February 2021

Check for updates

(c) Author(s) (or their employer(s)) 2021. Re-use permitted under CC BY-NC. No commercial re-use. See rights and permissions. Published by BMJ.

To cite: Packard C Chapman MJ, Sibartie M, et al. Heart Epub ahead of print: [please include Day Month Year]. doi:10.1136/ heartinl-2020-318760

\section{ABSTRACT}

Elevated levels of low-density lipoprotein cholesterol (LDL-C) are associated with increased risk of coronary heart disease and stroke. Guidelines for the management of dyslipidaemia from the European Society of Cardiology (ESC) and the European Atherosclerosis Society (EAS) were updated in late 2019 in light of recent intervention trials involving the use of innovative lipid-lowering agents in combination with statins. The new guidelines advocate achieving very low LDL-C levels in individuals at highest risk, within the paradigm of 'lower is better'. With the advent of combination therapy using ezetimibe and/or proprotein convertase subtilisin/kexin type 9 inhibitors in addition to statins, the routine attainment of extremely low LDL-C levels in the clinic has become a reality. Moreover, clinical trials in this setting have shown that, over the 5-7 years of treatment experience to date, profound $L D L-C$ lowering leads to further reduction in cardiovascular events compared with more moderate lipid lowering, with no associated safety concerns. These reassuring findings are bolstered by genetic studies showing lifelong very low LDL-C levels ( $<1.4 \mathrm{mmol} / \mathrm{L}$; $<55 \mathrm{mg} / \mathrm{dL}$ ) are associated with lower cardiovascular risk than in the general population, with no known detrimental health effects. Nevertheless, long-term safety studies are required to consolidate the present evidence base. This review summarises key data supporting the ESC/EAS recommendation to reduce markedly LDL-C levels, with aggressive goals for LDL-C in patients at highest risk, and provides expert opinion on its significance for clinical practice.

\section{INTRODUCTION}

All clinicians attest to the fact that guidelines, although helpful, do not match day-to-day practice. Many patients do not fit neatly into the categorised recommendations, and judgement must be made on the most prudent course of action. The recently updated guidelines for management of dyslipidaemia from the European Society of Cardiology (ESC) and European Atherosclerosis Society (EAS) present a further challenge since they recommend aggressive goals for low-density lipoprotein cholesterol (LDL-C) lowering: $<1.8 \mathrm{mmol} / \mathrm{L}(<70 \mathrm{mg} / \mathrm{dL}$ ) for patients at high risk of atherosclerotic cardiovascular disease (ASCVD); $<1.4 \mathrm{mmol} / \mathrm{L}(<55 \mathrm{mg}$ / $\mathrm{dL})$ for patients at very high risk or with clinically evident ASCVD; and $<1.0 \mathrm{mmol} / \mathrm{L}(<40 \mathrm{mg} /$ dL) for very high-risk patients who experienced a second vascular event within 2 years. ${ }^{1}$ The ESC/ EAS approach of recommending these very low goals for LDL-C is in distinction to the recent
American College of Cardiology/American Heart Association guidelines where a threshold of $70 \mathrm{mg}$ $\mathrm{dL}$ was identified as a level at which addition of non-statin to maximally tolerated statin therapy could be considered, but no lower goal was set. ${ }^{2}$ The European guideline writers believe that the science is strong enough to state that 'no level of LDL-C below which benefit ceases or harm occurs has been defined'. ${ }^{1}$ This approach prompts a number of questions-how do we translate this into clinical practice? Should it be applied universally or selectively? This review briefly lays out the evidence that led the writers to recommend the most aggressive goals yet for LDL-C lowering, and explores a casebased interpretation of the practicality of intensive LDL-C lowering.

\section{WHAT IS THE RELATIONSHIP BETWEEN LDL-C AND CARDIOVASCULAR DISEASE RISK?}

LDL, the main carrier of cholesterol in the blood, is a causal factor for ASCVD. ${ }^{34}$ Non-high-density lipoprotein (HDL) cholesterol, of which LDL-C is the major component, exhibits an approximate log-linear association (a doubling of risk per unit increase) with incidence of disease across the concentration range seen in the population (figure 1A). ${ }^{45}$ Moreover, this continuous relationship is replicated in genetic studies (figure 1B) and outcome trials of LDL-C lowering (figure $1 \mathrm{C}) .{ }^{46}$ It is the robustness and reproducibility of the association that constitutes the first pillar of evidence for the ESC/EAS 'lower is better' therapeutic paradigm. ${ }^{1}$ Further, it is now recognised that the cumulative exposure of the artery wall to high LDL-C over time is critical. ${ }^{4}$ This concept is helpful in understanding the early appearance of ASCVD in people with inherited high LDL-C, as in familial hypercholesterolaemia (FH). ${ }^{347}$

In the management of other risk factors for ASCVD, such as blood pressure and blood glucose, a balance must be struck between the risk of having a high level (and accelerated atherosclerosis) and problems linked to too low a level (hypotension, hypoglycaemia). ${ }^{8}$ Management of LDL-C requires a distinct approach since there appears to be no 'downside' to profound lowering of this lipoprotein. ${ }^{48}$ The key question is: can we lower LDL-C into the proximity of the goals identified in the 2019 ESC/EAS guidelines without detriment to the patient? This is a particularly pertinent issue in secondary prevention where there is a perceived need to immediately and aggressively decrease the 
exposure of atherosclerotic lesions to LDL-C with the objective of inducing lesion stabilisation and regression. ${ }^{9}$

\section{WHAT IS THE EVIDENCE THAT INTENSIVE LDL-C LOWERING IS BENEFICIAL?}

LDL-C lowering with statins alone and in combination with ezetimibe and proprotein convertase subtilisin/kexin type 9 (PCSK9) inhibitors has been remarkably successful as an intervention strategy. Indeed, since the 1980 s, the LDL-C concentration used for inclusion into cardiovascular outcome studies has dropped steadily-from $>4.0 \mathrm{mmol} / \mathrm{L}(155 \mathrm{mg} / \mathrm{dL})$ in early statin trials to $>1.8 \mathrm{mmol} / \mathrm{L}$ in the latest combination therapy trials-and so, of course, has the mean LDL-C concentration achieved (figure 2). ${ }^{4}$ Substantial numbers of patients have now been exposed to LDL-C levels well below $1.3 \mathrm{mmol} / \mathrm{L}(50 \mathrm{mg} / \mathrm{dL}) .{ }^{10}{ }^{11}$ In terms of clinical benefit, there has been a stepwise decrement in ASCVD risk as LDL-C was reduced, and the 'rule of thumb' deduced from metaregression analysis is that a $1.0 \mathrm{mmol} / \mathrm{L}$ reduction in $\mathrm{LDL}-\mathrm{C}$ leads to a $22 \%$ relative risk reduction. ${ }^{12}$

As evidence that 'lower is better' accrued, goals for LDL-C have evolved (figure 2). The studies that influenced recommendations included trials of statin versus placebo, more versus less intensive statin therapy, and statin monotherapy versus combination treatment. Although specific LDL-C goals were not tested, all the drugs in these studies act on the same final mechanism-stimulation of LDL clearance from the circulation. Thus, it can be argued that, by proxy, ever more aggressive LDL-C goals were being assessed, and no floor has been uncovered below which further LDL-C reduction did not lead to incremental benefit. The Justification for the Use of statins in Prevention: an Intervention Trial Evaluating Rosuvastatin (JUPITER) study recruited participants with LDL-C $<3.4 \mathrm{mmol} / \mathrm{L}$. Compared with placebo, rosuvastatin lowered LDL-C by $50 \%$ and significantly reduced occurrence of cardiovascular events by $44 \%{ }^{13}$ Further LDL-C reductions, beyond those seen with statin therapy alone, were achieved in IMProved Reduction of Outcomes: Vytorin Efficacy International Trial (IMPROVE-IT). Here, patients receiving placebo with optimised statin therapy had a median LDL-C of $1.8 \mathrm{mmol} / \mathrm{L}$ while those receiving ezetimibe plus statin had a level of $1.4 \mathrm{mmol} / \mathrm{L}$. Combination therapy led to a modest but significant $6.4 \%$ risk reduction over 7 years of follow-up. ${ }^{14}$ It is noteworthy that treatment with simvastatin plus ezetimibe resulted in a median time-weighted LDL-C of $1.4 \mathrm{mmol} / \mathrm{L}$ (from a baseline of $2.4 \mathrm{mmol} / \mathrm{L}$ ) demonstrating that for many patients at very high risk, the new ESC/EAS goal can be reached with generically available oral therapies. ${ }^{14}$

Inhibition of PCSK9 with the monoclonal antibodies evolocumab and alirocumab, and more recently with inclisiran (an RNA-based agent that blocks PCSK9 synthesis), ${ }^{15}$ has made it possible to use combination therapy to attain even lower LDL-C levels. The Further cardiovascular OUtcomes Research with PCSK9 Inhibition in subjects with Elevated Risk (FOURIER) trial randomised patients with ASCVD and LDL-C levels $\geq 1.8 \mathrm{mmol} / \mathrm{L}$, despite being on a statin, to evolocumab or placebo. ${ }^{11}$ The PCSK9 inhibitor lowered LDL-C by $59 \%$ to a median of $0.8 \mathrm{mmol} / \mathrm{L}(30 \mathrm{mg} / \mathrm{dL})$ and reduced risk of the primary endpoint (composite of cardiovascular death, myocardial infarction (MI), stroke, hospitalisation for unstable angina or coronary revascularisation) by $15 \%$ over a median of 2.2years follow-up. ${ }^{11}$ Analysis of patients achieving the lowest LDL-C levels revealed that reductions in risk were still evident even when LDL-C was reduced below $0.7 \mathrm{mmol} / \mathrm{L}(25 \mathrm{mg} /$ $\mathrm{dL}$ ) (or even $0.3 \mathrm{mmol} / \mathrm{L}(10 \mathrm{mg} / \mathrm{dL})$ ). ${ }^{16}$ ODYSSEY Outcomes randomised patients with a recent acute coronary syndrome event and LDL-C $\geq 1.8 \mathrm{mmol} / \mathrm{L}$ to alirocumab or placebo on top of maximally tolerated doses of statins. Alirocumab treatment decreased LDL-C by $63 \%$ and was associated with a $15 \%$ reduction in risk of the primary endpoint (composite of death from coronary heart disease, non-fatal MI, fatal or non-fatal ischaemic stroke or unstable angina requiring hospitalisation) after a median follow-up of 2.8 years. ${ }^{17}$ The relative risk reduction with inclisiran treatment is being examined in the ongoing ORION-4 trial. $^{18}$

The total benefit gained from profound LDL-C lowering was assessed by examining the impact of study drugs on total events within the follow-up period, that is, first occurrence of an ASCVD endpoint plus subsequent ASCVD events. In IMPROVE-IT, for example, first events accounted for only $56 \%$ of the overall number of recorded cardiovascular endpoints; total events prevented by more aggressive LDL-C lowering were approximately double that of the primary endpoint. ${ }^{19}$ FOURIER reported an $18 \%$ greater reduction in total cardiovascular events in patients on evolocumab compared with those on placebo, over 2.2 years of follow-up. ${ }^{20}$ In ODYSSEY Outcomes, patients receiving alirocumab had $13 \%$ fewer total non-fatal events and $17 \%$ fewer fatal events than those receiving placebo, over 2.8 years of follow-up. ${ }^{21}$ Thus, in the high-risk populations studied in intensive LDL-lowering trials, evaluation of total cardiovascular events prevented makes this therapeutic strategy even more compelling.

\section{WHAT ARE THE RISKS OF NATURALLY OCCURRING LOW LDL-C, OR INTENSIVELY LOWERING LDL-C?}

Cholesterol is an essential molecule with many important cellular functions. ${ }^{4}$ Cells can acquire the lipid from circulating LDL or synthesise it for themselves. Presumably because the latter route is available to all tissues, very low levels of LDL are not associated with any known metabolic abnormalities or health concerns. ${ }^{22}$ Naturally occurring low LDL-C levels are present in a number of populations, and virtually all of us were born with LDL-C below $1.0 \mathrm{mmol} / \mathrm{L}$ - a concentration sufficient to support neonatal organ formation during which cholesterol requirements are very high. ${ }^{23}$ Lifelong LDL-C levels below $1.3 \mathrm{mmol} / \mathrm{L}$ have been observed in hunter-gatherer societies with no evidence of related health risks. ${ }^{22}$ Likewise, studies of individuals with very low levels due to genetic variants that promote LDL removal, such as PCSK9 loss of function (where LDL-C is $<0.39 \mathrm{mmol} / \mathrm{L}$ ) have not identified any major adverse outcomes associated with these inherited conditions while ASCVD risk is low. ${ }^{22} 24$

Risks associated with pharmacological LDL-C lowering can be divided into (1) risks linked to profoundly reducing LDL-C in people in whom it has been high for many years, and (2) adverse reactions associated with long-term use of hypolipidaemic agents. Statins are the benchmark and have been subject to intense investigation over decades of follow-up. ${ }^{121225-28}$ There is widespread acceptance that these drugs have a good safety profile and offer persisting benefit. ${ }^{27}$ Side effects have been identified and quantified, such as an increased propensity to develop type 2 diabetes at a frequency of approximately 1 case per 1000 patients treated for 1 year. ${ }^{29}$ When this is placed in an overall risk-benefit evaluation, most commentators consider that the benefit of ASCVD reduction far outweighs the diabetes risk. ${ }^{127} 29$

In the FOURIER study of evolocumab, $10 \%(n=2669 / 25982)$ of patients reached LDL-C levels $<0.5 \mathrm{mmol} / \mathrm{L}(19 \mathrm{mg} / \mathrm{dL})$. This subgroup exhibited the lowest risk of cardiovascular events, and there was no significant difference in treatment-emergent adverse events compared with those who had higher LDL-C on treatment 

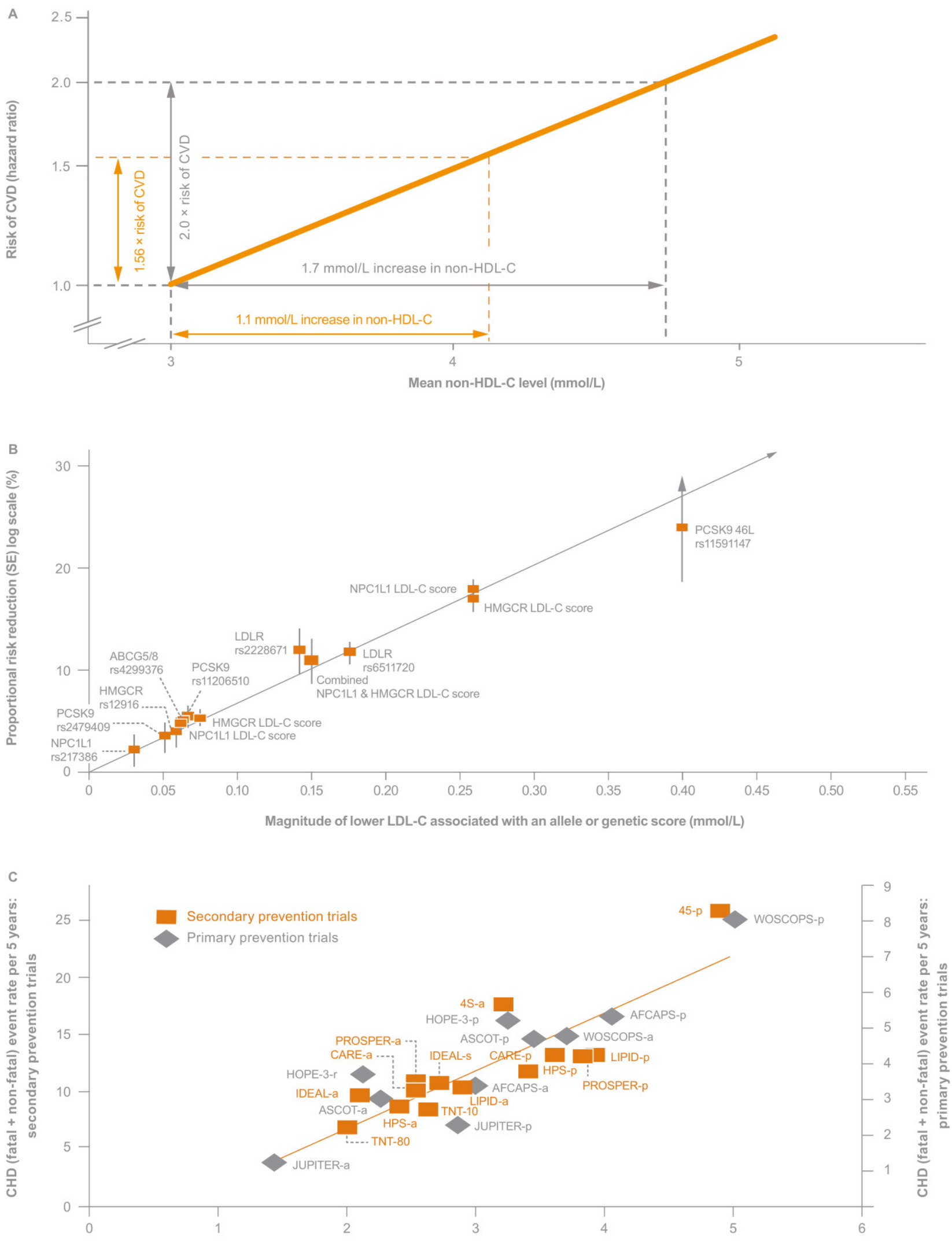

Mean pharmacologically achieved LDL-C level (mmol/L)

Figure 1 LDL-C and risk of ASCVD. (A) The approximately log-linear relationship between non-HDL-C and cardiovascular disease (CVD) risk as reported in epidemiological studies. The regression line and the quoted increase in CVD risk (1.56 x) per population standard deviation change in non-HDL-C (1.1 mmol/L) are taken from Di Angelantonio et a $F^{5}$. Also shown is the increase in non-HDL-C that gives rise to a doubling of risk. (B) the association of LDL-C with ASCVD risk in genetic studies ${ }^{6}$; and $(C)$ the relationship between achieved LDL-C and CHD event rate in lipid lowering trials. ${ }^{4}$ ASCVD, atherosclerotic cardiovascular disease; CHD, coronary heart disease; HDL-C, high-density lipoprotein cholesterol; LDL-C, low-density lipoprotein cholesterol; SE, standard error. Adapted with permission from (B) Ference et al ${ }^{6}$ and (C) Ference et al. ${ }^{4}$ 


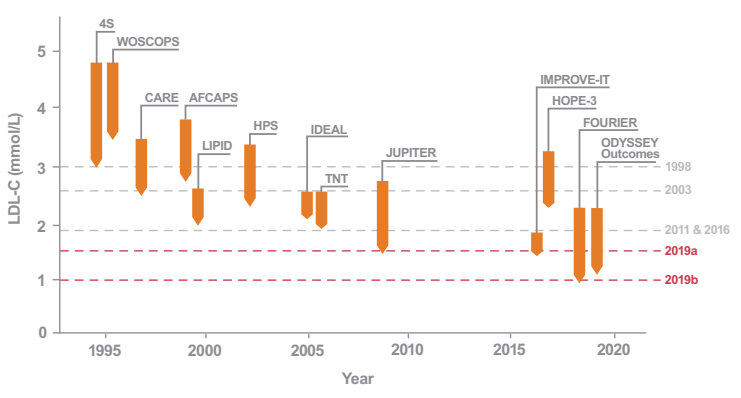

Figure 2 History of LDL-C lowering trials. This schematic depicts average baseline (top of orange arrow) and on-treatment LDL-C levels (bottom of orange arrow). Grey dotted lines represent previous recommended LDL-C ESC/EAS goals for intervention and the red dotted lines $(2019 \mathrm{a}, \mathrm{b})$ represent the current LDL-C ESC/EAS goals. ${ }^{134424950}$ ESC/EAS, European Society of Cardiology/European Atherosclerosis Society; LDL-C, low-density lipoprotein cholesterol.

(whether on active drug or placebo). ${ }^{16}$ In a substudy to assess any impact on cognition, the rates of neurological and neurocognitive events were similar in patients with LDL-C $<0.6 \mathrm{mmol} / \mathrm{L}$ $(23 \mathrm{mg} / \mathrm{dL})$ and those with LDL-C above this value. ${ }^{30}$ In IMPROVE-IT, more than 5000 patients receiving ezetimibe plus statin achieved an LDL-C $<1.3 \mathrm{mmol} / \mathrm{L}$, with approximately 1000 patients achieving levels $<0.8 \mathrm{mmol} / \mathrm{L}$. Over 7 years of follow-up, neither subgroup showed an increased frequency of side effects, including new-onset diabetes, haemorrhagic stroke or neurocognitive derangements. ${ }^{31}$ The risk of developing type 2 diabetes has been examined in the PCSK9 inhibitor trials and, to date, no excess incidence of diabetes or glucose intolerance has been reported in individual studies and in a meta-analysis of 39 randomised controlled trials. ${ }^{10} 113233$ These safety findings are supported with up to 5 years of data as observed in OSLER$1^{32}{ }^{34}$ However, genetic studies indicate that variations in the genes for PCSK9 and hydroxymethylglutaryl-CoA reductase (surrogates for the action of PCSK9 inhibitors and statins) are both equally linked to higher risk of diabetes. ${ }^{27}{ }^{35}$ Increased risk of haemorrhagic stroke has been a lingering concern from metaanalyses of the statin trials, particularly in patients with very low LDL-C levels. ${ }^{28}$ This issue was examined in the PCSK9 inhibitor studies and no evidence for higher rates of haemorrhagic stroke was detected. ${ }^{11161732}$

An important additional factor in the safety discussion is the mechanism of action of lipid-lowering drugs. While those increasing LDL clearance (statins, PCSK9 inhibitors, ezetimibe, bile acid sequestrants) by upregulating LDL receptors are not associated with a high risk of adverse events, blocking lipoprotein production with agents such as mipomersen and lomitapide carries a risk of complications associated with fat accumulation in the liver. ${ }^{1}$

Keeping in mind that our clinical trial experience of reducing LDL-C to very low levels with PCSK9 inhibitors is limited to about a 5-year horizon, the totality of evidence to date indicates that even at LDL-C levels below the goals recommended by the ESC/EAS, there is no discernible harm from either the very low level of LDL or from the drugs employed to induce intensive LDL-C lowering. This conclusion is the second pillar supporting the recommendation that aggressive LDL-C lowering is a safe and effective therapeutic strategy. There is, of course, an ongoing imperative for long-term pharmacovigilance of newer lipid-lowering agents along the lines of that achieved for statins. 112252628

\section{GUIDELINES AND GOALS FOR INTENSIVE LDL-C LOWERING IN THE 2020S}

The case for intensive LDL-C lowering is well made, and for most individuals we now have the means to achieve whatever goal is deemed most appropriate for their level of cardiovascular risk. This presents an opportunity for a treatment approach where the 'high-intensity statin' concept in patients at highest risk is replaced by a tailored 'high-intensity lipid-lowering' strategy. ${ }^{36}$ The challenge is how to implement this strategy given that in most patients achieving the new goals will require addon, non-statin LDL-C-lowering therapy such as ezetimibe and/ or a PCSK9 inhibitor (monoclonal antibody or inclisiran), or possibly bempedoic acid-an inhibitor of cholesterol synthesis with complementary action to that of statins. ${ }^{8} 1537$ For PCSK9 inhibitors, cost-effectiveness considerations have been discussed in recent publications ${ }^{38}$ and have led to promotion of a 'highest risk-highest benefit' approach in guidelines. ${ }^{1}{ }^{39}$ Results from studies such as EUROASPIRE $\mathrm{V}^{40}$ and DA VINCI ${ }^{41}$ indicate that achievement of the previous (2016) goals ${ }^{42}$ was already challenging. Addressing the newer, more ambitious LDL-C goals means that combination lipid-lowering therapy for many patients at high and very high risk will become the rule rather than the exception.

When deciding how aggressive an LDL-C-lowering regimen to prescribe, clinicians should be mindful that the absolute risk reduction is a function of both the absolute decrease in LDL-C concentration and the estimated ongoing ASCVD risk. The smaller the absolute drop in LDL-C, the less the relative risk reduction, and so the benefit gained from intervention depends on the risk status of the patient. ${ }^{11239}$ At low LDL-C levels (eg, patients on statin) further lowering is recommended primarily for those in the highest risk categories. ${ }^{1}{ }^{39}$ This approach is explored in figure 3 where we present typical patients with ASCVD at high/very high risk, who would fall into three of the categories of LDL-C goals set out in the guidelines. ${ }^{1}$

Patients considered at high enough risk to warrant treating to a goal of LDL-C $<1.8 \mathrm{mmol} / \mathrm{L}$ and a greater than $50 \%$ decrease from baseline levels include, as in case 1 (figure 3), those who are asymptomatic but have a cardiometabolic disorder or high LDL-C due to inherited conditions such as FH. On combination therapy, case 1 should achieve both goals. Patients at very high risk, such as case 2 , are recommended to reach an LDL-C $<1.4 \mathrm{mmol} / \mathrm{L}$ and a greater than $50 \%$ decrease from baseline levels. ${ }^{1}$ In this example, statin-associated muscle symptoms limited the dose of statin used, and while the patient should be maintained on the maximum tolerated dose, the LDL-C goal will likely only be achieved with combination therapy. ${ }^{43} \mathrm{~A}$ clinical judgement has to be made whether to (1) accept the slightly higher than optimal predicted LDL-C of $1.8 \mathrm{mmol} / \mathrm{L}$ on statin plus ezetimibe, while achieving a greater than $50 \%$ decrease from the notional baseline of $4.0 \mathrm{mmol} / \mathrm{L}$ (estimated from the measured LDL-C on statin monotherapy and the average LDL-C decrease on that statin dose), ${ }^{144}$ or (2) prescribe a PCSK9 inhibitor to achieve the more aggressive goal. The additional $0.9 \mathrm{mmol} / \mathrm{L}$ drop is predicted to deliver a further $20 \%$ reduction in risk ${ }^{12}$ and the cost-benefit decision will be dependent on the perceived ongoing ASCVD risk for this patient. Case 3 is an example of ASCVD that follows an aggressive course with a major coronary event occurring a relatively short time after the initial clinical 


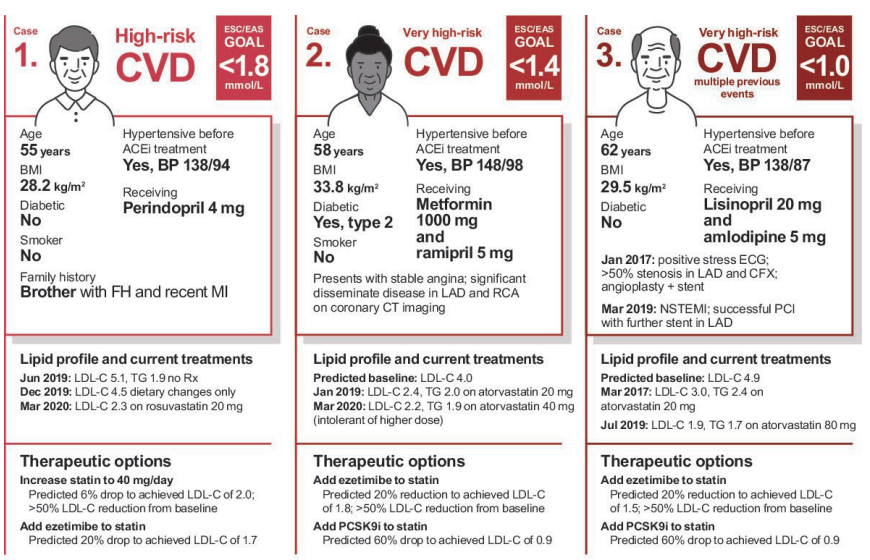

Figure 3 Patient scenarios. Cases of patients at high ASCVD risk being ascribed to regimens of increasingly intensive LDL-C lowering. LDL-C and triglyceride levels are given in $\mathrm{mmol} / \mathrm{L}$ (see online supplemental figure 1 for the $\mathrm{mg} / \mathrm{dL}$ version). The predicted LDL-C reductions of $20 \%$ for ezetimibe and $60 \%$ for PCSK9i are based on average published responses. ${ }^{14}$ Case 1 is a patient with probable $\mathrm{FH}$ on the basis of his high LDL-C and sibling with diagnosed FH. Note, the additional $6 \%$ reduction on $40 \mathrm{mg}$ rosuvastatin is based on the untreated LDL-C of $5.1 \mathrm{mmol} / \mathrm{L}$; the $20 \%$ drop on ezetimibe is calculated from the LDL-C on $20 \mathrm{mg}$ rosuvastatin. Case 2 is a woman with obesity, type 2 diabetes plus other risk factors (hypertension) with symptomatic ASCVD. Case 3 is a man with hypertension with repeat ASCVD events within a short time period (26 months). Note, when LDL-C levels are low-typically $<1.8 \mathrm{mmol} / \mathrm{L}$-laboratory measurement can be problematic especially if lipoprotein(a) or plasma triglyceride levels are high. ${ }^{46}$ The guidelines recommend the use of non-HDL-C or apolipoprotein B as secondary measures to assess the need for further lipid-lowering action when $\mathrm{LDL}-\mathrm{C}$ is low, as discussed in more detail. ${ }^{148} \mathrm{ACEi}$, angiotensinconverting-enzyme inhibitor; ASCVD, atherosclerotic cardiovascular disease; BMI, body mass index; BP, blood pressure; CFX, coronary circumflex artery; CVD, cardiovascular disease; ESC/EAS, European Society of Cardiology/European Atherosclerosis Society; FH, familial hypercholesterolaemia; LAD, coronary left anterior descending artery; LDL-C, low-density lipoprotein cholesterol; MI, myocardial infarction; NSTEMI, non-ST elevation Ml; $\mathrm{PCl}$, percutaneous coronary intervention; PCSK9i, proprotein convertase subtilisin/kexin type 9 inhibitor; RCA, right coronary artery; TG, plasma triglyceride.

presentation. Despite recommendations to use the maximum dose of a statin, the patient (as is common) was on a less than optimal dose of atorvastatin after angioplasty, ${ }^{45}$ which was only increased in steps to $80 \mathrm{mg}$ after the second event. While the new guidelines set experiencing a second vascular event 'within 2 years' as the benchmark for defining this highest risk category, ${ }^{1}$ application of clinical judgement would again lead to the adoption of the most aggressive goal of LDL-C $<1.0 \mathrm{mmol} / \mathrm{L}$.

In assessing progress towards goals, it should be noted that laboratory measurement of LDL-C at very low levels can present challenges especially when lipoprotein (a) or plasma triglyceride levels are elevated. ${ }^{46}{ }^{47}$ In this context, secondary goals relating to non-HDL-C or apolipoprotein B can be useful when judging whether to prescribe add-on therapy. ${ }^{148}$

Figure 4 summarises the types of conditions that would lead to intensification of LDL-C-lowering therapy, that is, combination of statins with ezetimibe and/or PCSK9 inhibitors. Identification of an individual with elevated risk of ASCVD, based on risk factor screening and evaluation of their SCORE (Systematic COronary Risk Estimation), ${ }^{1}$ or the presence of disorders that predispose to the development of ASCVD, such as type 2 diabetes or chronic kidney disease, would place them in the 'high risk' category with goals of LDL-C $<1.8 \mathrm{mmol} / \mathrm{L}$ and at least a 50\% reduction from baseline. Among individuals with established ASCVD (on imaging or clinical presentation) and comorbidities (chronic kidney disease or history of diabetes with organ damage, proteinuria, hypertension), vascular imaging can aid in judging the most appropriate LDL-C goal. Where it is clear that a patient has atherosclerotic disease that is following an aggressive course, as indicated by serial events within 2 years, a goal of $<1.0 \mathrm{mmol} / \mathrm{L}$ is warranted.

In conclusion, preventing ASCVD requires a coordinated response across primary and secondary care to diagnose and manage patients according to their risk profile. As the major modifiable causal factor for atherosclerosis, lowering LDL-C is the primary target and appropriate modification of dietary and lifestyle risk factors is the starting point. The updated 2019 ESC/ EAS guidelines recommend a move towards intensive lowering of LDL-C, which is warranted on scientific grounds and achievable in clinical practice. Implementation strategies are needed to apply current knowledge, guidelines and clinical judgement to the benefit of those at highest risk.

Acknowledgements The authors thank Laura Drought, PhD, from PharmaGenesis, London, UK, who provided editorial assistance during the preparation of the manuscript.

Contributors All authors contributed equally to the design and writing of the manuscript. All authors critically reviewed and edited the manuscript.

Funding Editorial assistance from PharmaGenesis London was funded by Amgen Europe $(\mathrm{GmbH})$. All authors wrote the paper, had full editorial responsibility for the content and did not receive any funding for this work.

Competing interests $\mathrm{CP}$ has received honoraria from Amgen, Daiichi Sankyo and Dalcor. JC has received research funding from Amgen, Kowa and Pfizer; and honoraria for speakers' bureau activities and consultancy from Amarin, Amgen, AstraZeneca, Daiichi Sankyo, Merck Sharp \& Dohme, Pfizer, Regeneron and Sanofi. UL has received honoraria for lectures from Amgen, Daiichi Sankyo, Novartis and Sanofi. LM has received honoraria for lectures and advisory work from Amarin, Amgen, Amryn, Mylan, Regeneron, Sanofi and Servier. MS is an employee of Amgen.

Patient consent for publication Not required.

Provenance and peer review Commissioned; externally peer reviewed.

Supplemental material This content has been supplied by the author(s). It has not been vetted by BMJ Publishing Group Limited (BMJ) and may not have been peer-reviewed. Any opinions or recommendations discussed are solely those of the author(s) and are not endorsed by BMJ. BMJ disclaims all liability and responsibility arising from any reliance placed on the content. Where the content includes any translated material, BMJ does not warrant the accuracy and reliability of the translations (including but not limited to local regulations, clinical guidelines, terminology, drug names and drug dosages), and is not responsible for any error and/or omissions arising from translation and adaptation or otherwise.

Open access This is an open access article distributed in accordance with the Creative Commons Attribution Non Commercial (CC BY-NC 4.0) license, which permits others to distribute, remix, adapt, build upon this work non-commercially, and license their derivative works on different terms, provided the original work is properly cited, appropriate credit is given, any changes made indicated, and the use is non-commercial. See: http://creativecommons.org/licenses/by-nc/4.0/.

\section{ORCID iD}

Chris Packard http://orcid.org/0000-0002-2386-9927

\section{REFERENCES}

1 Mach F, Baigent C, Catapano AL, et al. 2019 ESC/EAS guidelines for the management of dyslipidaemias: lipid modification to reduce cardiovascular risk. Eur Heart $J$ 2020;41:111-88.

2 Grundy SM, Stone NJ, Bailey AL, et al. 2018 guideline on the management of blood cholesterol: a report of the American College of Cardiology/American Heart Association Task Force on clinical practice guidelines. J Am Coll Cardiol 2019;73:3168-209

3 Borén J, Chapman MJ, Krauss RM, et al. Low-density lipoproteins cause atherosclerotic cardiovascular disease: pathophysiological, genetic, and therapeutic 


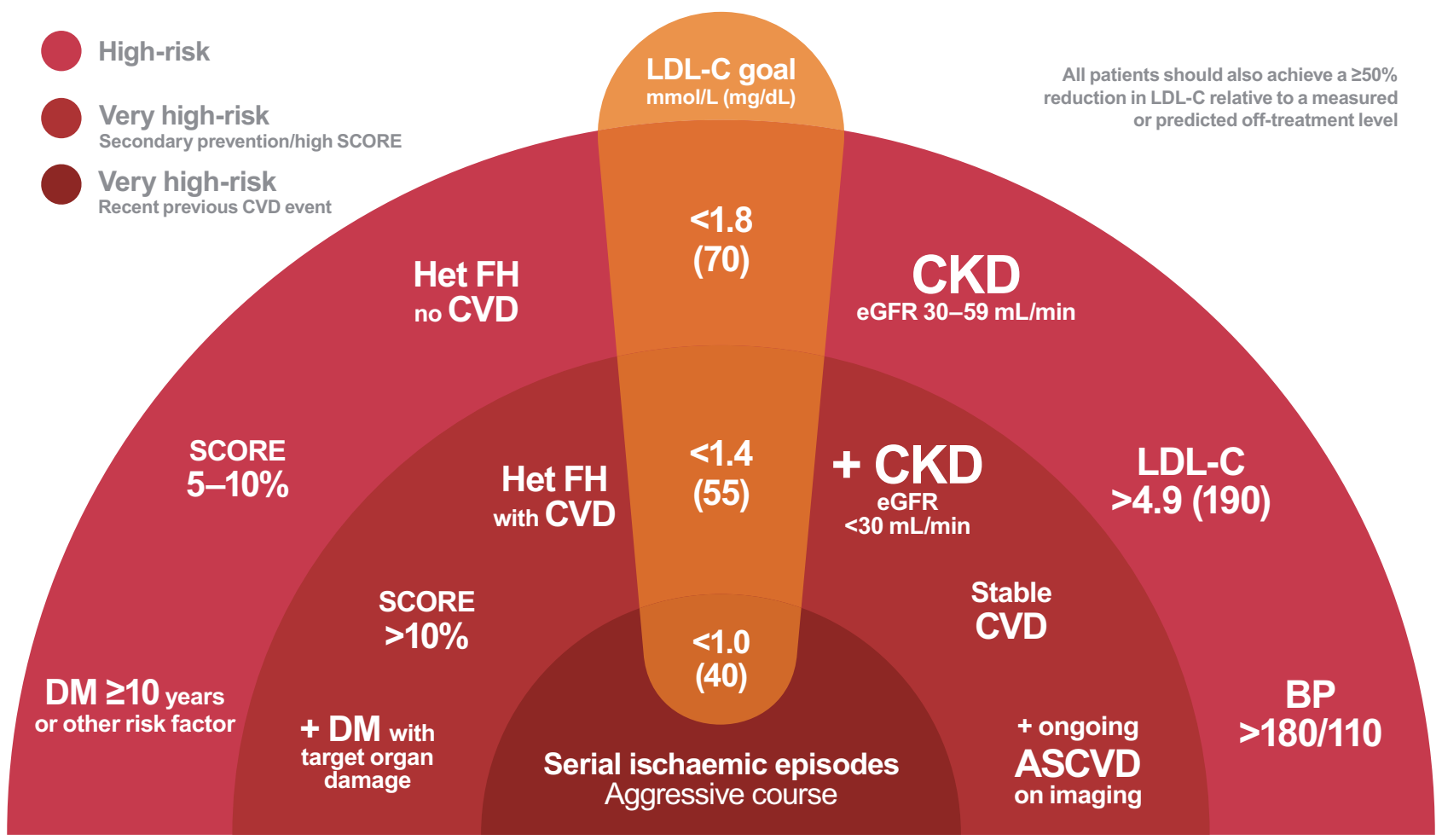

Figure 4 Schematic showing rationale for intensive LDL-C lowering. The outer circle represents patients at 'high risk' with an LDL-C goal of below $1.8 \mathrm{mmol} / \mathrm{L}(70 \mathrm{mg} / \mathrm{dL})$. Evidence of established disease, comorbidities, cardiometabolic disorders and multiple risk factors moves patients into the 'very high' risk middle circle, with a more ambitious target of below $1.4 \mathrm{mmol} / \mathrm{L}(55 \mathrm{mg} / \mathrm{dL})$. The most stringent goal of below $1.0 \mathrm{mmol} / \mathrm{L}(40 \mathrm{mg} / \mathrm{dL})$ is recommended for those with a particularly aggressive disease course ${ }^{1}$ (see online supplemental figure 2 for the $\mathrm{mg} / \mathrm{dL}(\mathrm{mmol} / \mathrm{L}$ ) version). Note, all patients should achieve an LDL-C reduction of $\geq 50 \%$ relative to a measured or predicted off-treatment LDL-C. ASCVD, atherosclerotic cardiovascular disease; BP, blood pressure; CKD, chronic kidney disease; CVD, cardiovascular disease; DM, diabetes mellitus; eGFR, estimated glomerular filtration rate; Het FH, heterozygous familial hypercholesterolaemia; LDL-C, low-density lipoprotein cholesterol; SCORE, Systematic COronary Risk Estimation.

insights: a consensus statement from the European Atherosclerosis Society Consensus Panel. Eur Heart J 2020;41:2313-30.

4 Ference BA, Ginsberg HN, Graham I, et al. Low-density lipoproteins cause atherosclerotic cardiovascular disease. 1. Evidence from genetic, epidemiologic, and clinical studies. A consensus statement from the European Atherosclerosis Society Consensus Panel. Eur Heart J 2017;38:2459-72.

5 Di Angelantonio E, Sarwar N, Perry P, et al. Major lipids, apolipoproteins, and risk of vascular disease. JAMA 2009;302:1993-2000.

6 Ference $B A$, Majeed $F$, Penumetcha $R$, et al. Effect of naturally random allocation to lower low-density lipoprotein cholesterol on the risk of coronary heart disease mediated by polymorphisms in NPC1L1, HMGCR, or both: a $2 \times 2$ factorial Mendelian randomization study. J Am Coll Cardiol 2015;65:1552-61.

7 Wiegman A, Gidding SS, Watts GF, et al. Familial hypercholesterolaemia in children and adolescents: gaining decades of life by optimizing detection and treatment. Eur Heart J 2015;36:2425-37.

8 Packard CJ. LDL cholesterol: how low to go? Trends Cardiovasc Med 2018;28:348-54.

9 Schubert J, Lindahl B, Melhus $\mathrm{H}$, et al. Low-density lipoprotein cholesterol reduction and statin intensity in myocardial infarction patients and major adverse outcomes: a Swedish nationwide cohort study. Eur Heart J 2021;42:243-52.

10 Robinson JG, Rosenson RS, Farnier M, et al. Safety of very low low-density lipoprotein cholesterol levels with alirocumab: pooled data from randomized trials. J Am Coll Cardiol 2017;69:471-82.

11 Sabatine MS, Giugliano RP, Keech AC, et al. Evolocumab and clinical outcomes in patients with cardiovascular disease. N Engl J Med 2017;376:1713-22.

12 Baigent C, Blackwell L, Emberson J, et al. Efficacy and safety of more intensive lowering of LDL cholesterol: a meta-analysis of data from 170,000 participants in 26 randomised trials. Lancet 2010;376:1670-81.

13 Ridker PM, Danielson E, Fonseca FAH, et al. Rosuvastatin to prevent vascular events in men and women with elevated C-reactive protein. $N$ Engl J Med 2008;359:2195-207

14 Cannon CP, Blazing MA, Giugliano RP, et al. Ezetimibe added to statin therapy after acute coronary syndromes. N Engl J Med 2015;372:2387-97.
15 Brandts J, Ray KK. Clinical implications and outcomes of the ORION Phase III trials. Future Cardiol 2020. doi:10.2217/fca-2020-0150. [Epub ahead of print: 21 Dec 2020].

16 Giugliano RP, Pedersen TR, Park J-G, et al. Clinical efficacy and safety of achieving very low LDL-cholesterol concentrations with the PCSK9 inhibitor evolocumab: a prespecified secondary analysis of the FOURIER trial. Lancet 2017;390:1962-71.

17 Schwartz GG, Steg PG, Szarek M, et al. Alirocumab and cardiovascular outcomes after acute coronary syndrome. N Engl J Med 2018;379:2097-107.

18 Stoekenbroek RM, Kallend D, Wijngaard PL, et al. Inclisiran for the treatment of cardiovascular disease: the ORION clinical development program. Future Cardiol 2018;14:433-42.

19 Murphy SA, Cannon CP, Blazing MA, et al. Reduction in total cardiovascular events with ezetimibe/simvastatin post-acute coronary syndrome: the IMPROVE-IT trial. J Am Coll Cardiol 2016;67:353-61.

20 Murphy SA, Pedersen TR, Gaciong ZA, et al. Effect of the PCSK9 inhibitor evolocumab on total cardiovascular events in patients with cardiovascular disease: a prespecified analysis from the FOURIER trial. JAMA Cardiol 2019:4:613-9.

21 Szarek M, White HD, Schwartz GG, et al. Alirocumab reduces total nonfatal cardiovascular and fatal events: the ODYSSEY OUTCOMES trial. J Am Coll Cardiol 2019;73:387-96.

22 Masana L, Girona J, Ibarretxe D, et al. Clinical and pathophysiological evidence supporting the safety of extremely low LDL levels-The zero-LDL hypothesis. J Clin Lipidol 2018;12:292-9.

23 Woollett $L$, Heubi JE. Fetal and neonatal cholesterol metabolism. In: Feingold KR, Anawalt B, Boyce A, eds. Endotext [Internet]. South Dartmouth (MA): MDText.com, 2016.

24 Cohen JC, Boerwinkle E, Mosley TH, et al. Sequence variations in PCSK9, low LDL, and protection against coronary heart disease. N Engl J Med 2006;354:1264-72.

25 Ford I, Murray H, McCowan C, et al. Long-term safety and efficacy of lowering low-density lipoprotein cholesterol with statin therapy: 20-year follow-up of West of Scotland Coronary Prevention Study. Circulation 2016:133:1073-80.

26 Gupta A, Mackay J, Whitehouse A, et al. Long-term mortality after blood pressurelowering and lipid-lowering treatment in patients with hypertension in the AngloScandinavian Cardiac Outcomes Trial (ASCOT) Legacy study: 16-year follow-up results of a randomised factorial trial. Lancet 2018;392:1127-37. 
27 Mach F, Ray KK, Wiklund O, et al. Adverse effects of statin therapy: perception vs. the evidence - focus on glucose homeostasis, cognitive, renal and hepatic function, haemorrhagic stroke and cataract. Eur Heart J 2018;39:2526-39.

28 Collins R, Reith C, Emberson J, et al. Interpretation of the evidence for the efficacy and safety of statin therapy. Lancet 2016;388:2532-61.

29 Preiss D, Sattar N. Statins and the risk of new-onset diabetes: a review of recent evidence. Curr Opin Lipidol 2011;22:460-6.

30 Giugliano RP, Mach F, Zavitz K, et al. Cognitive function in a randomized trial of evolocumab. N Engl J Med 2017;377:633-43.

31 Giugliano RP, Wiviott SD, Blazing MA, et al. Long-term safety and efficacy of achieving very low levels of low-density lipoprotein cholesterol: a prespecified analysis of the IMPROVE-IT trial. JAMA Cardiol 2017;2:547-55.

32 Koren MJ, Sabatine MS, Giugliano RP, et al. Long-term efficacy and safety of evolocumab in patients with hypercholesterolemia. J Am Coll Cardiol 2019;74:2132-46

33 Guedeney P, Giustino G, Sorrentino S, et al. Efficacy and safety of alirocumab and evolocumab: a systematic review and meta-analysis of randomized controlled trials. Eur Heart J 2019. doi:10.1093/eurheartj/ehz430. [Epub ahead of print: 03 Jul 2019].

34 Chapman MJ, Ginsberg HN. Evolocumab treatment of hypercholesterolemia in OSLER-1: enduring efficacy, tolerability, and safety over 5 years. J Am Coll Cardiol 2019:74:2147-9.

35 Ference BA, Robinson JG, Brook RD, et al. Variation in PCSK9 and HMGCR and risk of cardiovascular disease and diabetes. N Eng/ J Med 2016;375:2144-53.

36 Masana L, Pedro-Botet J, Civeira F. IMPROVE-IT clinical implications. Should the "highintensity cholesterol-lowering therapy" strategy replace the "high-intensity statin therapy" ? Atherosclerosis 2015;240:161-2.

37 Ray KK, Bays HE, Catapano AL, et al. Safety and efficacy of bempedoic acid to reduce LDL cholesterol. N Engl J Med 2019;380:1022-32.

38 Fonarow GC, van Hout B, Villa G, et al. Updated cost-effectiveness analysis of evolocumab in patients with very high-risk atherosclerotic cardiovascular disease. JAMA Cardiol 2019;4:691-5.

39 Annemans L, Packard CJ, Briggs A, et al. 'Highest risk-highest benefit' strategy: a pragmatic, cost-effective approach to targeting use of PCSK9 inhibitor therapies. Eur Heart J 2018;39:2546-50.
40 De Backer G, Jankowski P, Kotseva K, et al. Management of dyslipidaemia in patients with coronary heart disease: results from the ESC-EORP EUROASPIRE V survey in 27 countries. Atherosclerosis 2019;285:135-46.

41 Ray KK, Molemans B, Schoonen WM, et al. EU-wide cross-sectional observational study of lipid-modifying therapy use in secondary and primary care: the DA VINCI study. Eur J Prev Cardiol 2020. doi:10.1093/eurjpc/zwaa047

42 Catapano AL, Graham I, De Backer G, et al. 2016 ESC/EAS guidelines for the management of dyslipidaemias. Eur Heart J 2016;37:2999-3058.

43 Stroes ES, Thompson PD, Corsini A, et al. Statin-associated muscle symptoms: impact on statin therapy-European Atherosclerosis Society Consensus Panel statement on assessment, aetiology and management. Eur Heart $J$ 2015;36:1012-22.

44 European Medicines Agency. Atorvastatin Summary of Product Characteristics. 2020. available. Available: https://www.medicines.org.uk/emc/product/2956 [Accessed 13 July 2020].

45 Ferrières J, Rouyer MV, Lautsch D, et al. Suboptimal achievement of low-density lipoprotein cholesterol targets in French patients with coronary heart disease. Contemporary data from the DYSIS II ACS/CHD study. Arch Cardiovasc Dis 2017;110:167-78

46 Willeit P, Yeang C, Moriarty PM, et al. Low-density lipoprotein cholesterol corrected for lipoprotein(a) cholesterol, risk thresholds, and cardiovascular events. J Am Heart Assoc 2020;9:e016318.

47 Sampson M, Ling C, Sun Q, et al. A new equation for calculation of low-density lipoprotein cholesterol in patients with normolipidemia and/or hypertriglyceridemia. JAMA Cardiol 2020;5:540-8.

48 Langlois MR, Nordestgaard BG, Langsted A, et al. Quantifying atherogenic lipoproteins for lipid-lowering strategies: consensus-based recommendations from EAS and EFLM. Clin Chem Lab Med 2020;58:496-517.

49 Erhardt LR, Gotto A. The evolution of European guidelines: changing the management of cholesterol levels. Atherosclerosis 2006;185:12-20.

50 Reiner Z, Catapano AL, De Backer G, et al. ESC/EAS guidelines for the management of dyslipidaemias: the Task Force for the management of dyslipidaemias of the European Society of Cardiology (ESC) and the European Atherosclerosis Society (EAS). Eur Heart J 2011;32:1769-818. 